\title{
Message from the Editor
}

This is the seventh volume of Transactions of The Japan Institute of Electronics Packaging (Trans. JIEP, English version). Trans. JIEP was first published in 2008. It aims to provide the information on electronics packaging (Jisso) technologies that includes assembling, packaging, mounting, interconnection, electromagnetic characteristics, and so on, to share new ideas and achievements with worldwide engineers and scientists in these areas. By an effort of former editors-in-chief, Prof. H. Tomokage, Prof. I. Koiwa and Dr. K. Hashimoto, Trans. JIEP has firmly established its status as a representative technical journal in the Jisso technologies.

This-year's volume contains 18 technical papers and one tutorial paper. These papers involve various newest Jisso technologies such as 3-D packaging, optical interconnection, thermal management, power electronics and so on. We are sure that they will provide much valuable and helpful information to you. Although all the papers in this volume are from Japanese engineers, we surely welcome the submission of high-quality papers from overseas countries. We hope that you can publish your important and remarkable achievements through Trans. JIEP, so that we can stimulate each other by sharing the ideas and technologies through Trans. JIEP, and make it become a true international journal in the Jisso technologies. The deadline of manuscript submission for the next volume is planned in the end of June, 2015. We are waiting for your submission.

Finally, as the editor-in-chief, I would like to express my sincere appreciation to all the authors for their contributions, and to all the reviewers and all the editorial committee members for their hard voluntary work on this publication.

December 10, 2014

Jianqing Wang

Editor-in-Chief

Transactions of The Japan Institute of Electronics Packaging Professor, Nagoya Institute of Technology 